\title{
Romatoid artrit - tedavi prensipleri: Ne zaman geçiş yapalım?
}

\author{
Rheumatoid arthritis - treatment strategies: Switch time
}

\author{
Didem Arslan \\ Çukurova Üniversitesi Tıp Fakültesi, İç Hastalıkları Anabilim Dalı Romatoloji Bilim Dalı, Adana, Türkiye
}

Öz

Romatoid artrit, esas olarak sinoviyal eklemleri tutan kronik, sistemik, inflamatuvar eklem hastalığıdır. Erken tanı konması, yüksek hastalık aktivitesi, otoantikor pozitifliği ve erken eklem hasarı gibi kötü prognostik faktörlere sahip hastalarda optimal terapötik başarı için anahtardır. Tedavi algoritmalarında, kompozit indeksler ile hastalık aktivitesi ölçümleri, treat-to-target tedavi stratejileri ve tedavilerin etki ve yan etkiler açısından uygun şekilde izlemleri yer alır. Remisyon veya en azından düşük hastalık aktivitesi olarak belirlenen tedavi hedefi sağlanana kadar tedavi modifikasyonları yapılmalıdır. Hedef sağlandığında ve sürdürülebildiğinde, doz azaltımına gidilebilir. Çoğu hastada tedavi yanıtları kabul edilebilir düzeylerde olsa da, mevcut tedavilere yanıt her zaman mümkün olamamaktadır. Gelecekte yapılacak daha kapsamlı çalışmalar ile bireyselleştirilmiş tedavilerin geliştirilmesi mümkün olabilecektir.

Anahtar Sözcükler: Romatoid artrit, ilaç tedavisi, yönetim.

\begin{abstract}
Rheumatoid is a chronic, systemic, inflammatory disorder that primarily involves synovial joints. Early diagnosis is important for the therapeutic success in patients with poor prognostic factors such as high disease activity, high titers of autoantibodies and joint injury in early stages of disease. Algorithms for treatment include using composite indexes, disease activity measures, treat-to-target strategies and appropriate follow-up for effects and side effects. Modifications for treatment should be made until reaching the goal as determined before to be remission or at least low disease activity. When the goal is reached and sustained, dose reduction could be applied. Although for most of the patients, the goal of the therapy is achieved, the results are not always acceptable. Therefore, more detailed studies should be planned for developing individualized therapies.
\end{abstract}

Keywords: Rheumatoid arthritis, medical treatment, management.

\section{Giriş}

Romatoid artrit (RA) tedavisi, yaklaşık olarak yarım asırlık, minimal etkili veya etkisiz, yüksek toksisiteli birkaç terapötik ajandan pek çok alternatifi olan geniş yelpazeli bir ilaç portföyüne uzanan bir yolculukla, oldukça yüz güldürücü bir noktaya ulaşmıştır. Bütün bunlara rağmen uzun süreli ve yakın takip gerektiren zorlu bir süreçtir. Erken artrit klinikleri ile birlikte, erken başlanılan tedavilerde hedefe ulaşma oranları daha yüksektir. Yeni sınıflandırma kriterleri de daha erken hastaların tanı almasını sağlamaktadır (1).
Treat-to-Target (T2T) stratejileri ile tedavi modifikasyonları ve American Collage of Rheumatology (ACR) ve European Leageue Against Rheumatism (EULAR) klinik sonuç kriterleri ile iyi belirlenmiş tedavi hedefleri, başarılı sonuçlar alınmasını sağlamıştır (2). Düşük hastalık aktivitesi yerine remisyon hedeflenen hastalarda ilaçsız remisyon oranları daha yüksek olmakla birlikte bu sonuç daha iyi fiziksel fonksiyon sağlamamıştır. Tedavi hedefi olarak ultrason remisyonu belirlendiğinde ise hastalar daha yoğun bin remisyonu hedeflemek RA hastaları için faydalı değildir. 
Remisyon veya düşük hastalık aktivitesi hedefleri belirlenirken mutlaka fonksiyonel kapasite gibi ek hedefler de hasta bazında belirlenmelidir.

Hastalık aktivitesinin göstergeleri:

Hassas ve şiş eklem sayıları, ağrı, hasta ve değerlendirici hastalık aktivitesi global değerlendirmeleri (INR), eritrosit sedimantasyon hIzI (ESH), C-reaktif protein (CRP), sabah tutukluğu süresi ve yorgunluk gibi komponentleri kapsar. Ek olarak, Fiziksel fonksiyon ölçütleri (HAQ), Sağlık durumu ölçütleri (SF 36) de çalışılmalıdır. Hastalık aktivitesi, hastanın raporladığı RADAI (3), RADAR (4), RAPID3 skoru (5) gibi araçlarla ölçülebilir.

\section{Kompozit biyomarker skorlaması:}

Multipl biomarker hastalık aktivitesi testi ve skoru olup klinik aktiviteyle iyi korelasyon göstermektedir (6).

\section{Tedavinin izleminde kullanılan yanıt kriterleri:}

ACR20, 50, 70 (Hybrid-ACR, ACR-N yanitı) ve EULAR yanıt kriterleridir (iyi, orta). Tedavi neticesinde esas varılmak istenen hedef remisyon olmalıdır. Remisyonun, hastaya ve topluma, fonksiyonel düzelme, radyolojik ilerleme olmaması, yaşam kalitesinde artma, iş gücü kazancı, sosyo-ekonomik kazanç gibi faydaları nedeniyle olumlu yansımaları olacağı muhakkaktır (7).

\section{Remisyon için kullanılan kriterler:}

Disease activity score (DAS)-28 Remisyonu, CDAI (clinical disease activity index) Remisyonu, SDAI (simplified disease activity index) Remisyonu ve ACR/EULAR Boolean Remisyon yanıtıdır.

DAS-28: Remisyon <2,6 / Düşük hastalık aktivitesi HA (LDA) $<3,2$ / Orta HA ve $<5,1$.

SDAl: Remisyon $\leq 3,3$ / Düşük HA(LDA) <11/ Orta $\mathrm{HA} \leq 26$.

CDAl: Remisyon $\leq 2,8$ / Düşük $\mathrm{HA}($ LDA $)<10$ / Orta $\mathrm{HA}<22$.

ACR/EULAR Boolean: Remisyon $\leq 4$ olarak tanımlanmaktadır.

RA için daha efektif tedaviler sağlandığından beri çalışmalar göstermiştir ki, (SDAI) $\leq 3,3$ ile sadece hastalık aktivitesi değil aynı zamanda radyografik progresyon da azalmıştır. Remisyonun uygulanabilirliği ve faydalılığı ışığında ACR/ EULAR 2011 remisyon kriterleri geliştirilmiştir. Bu kriterler Boolean tanımlamasını (hassas ve şiş eklem sayıları $\leq 1$ veya CRP $\leq 1 \mathrm{mg} / \mathrm{dl}$ ve beraberinde 0-10 skalasında hasta-raporlu global değerlendirme skalasını $\leq 1$ ) veya indeks bazlı bir tanımlamayı (SDAI $\leq 3,3$ ) kapsamaktadır (8).

RA tedavisi için bazı kılavuzlar geliştirilmektedir. $\mathrm{Bu}$ kılavuzlar, hekimlerin tedavi hedefine ulaşmasında kolaylık sağlamaktadır. EULAR tarafından da en son 2016 yılında güncellenen romatoid artrit tedavi kılavuzu mevcuttur (9).

Bu kılavuzda tanımlanan kötü prognostik faktörler şöyledir: Konvansiyonel sentetik hastalık modifiye edici ilaç (csDMARD) tedavisine rağmen orta/yüksek hastalık aktivitesi, akut faz gösterge düzeylerinin yüksekliği, çok sayıda şiş eklem olması, yüksek düzeyde RF ve/veya CCP titreleri, erken erozyon gelişimi veya bunların kombinasyonu.

Bu kılavuzda önerilen ana tedavi prensipleri şöyledir:

- RA'ı hastaların tedavisi, en iyi sağlık hizmetini hedef almalı ve hasta ile hekimin ortak kararına dayanmalıdır.

- Tedavi kararları, hastalık aktivitesi ve diğer hasta faktörlerine (yapısal hasarın progresyonu, komorbiditeler ve güvelik konuları vb.) dayanmalıdır.

- RA'lı hastalar primer olarak romatologlar tarafından takip edilmelidir.

- RA yüksek kişisel, medikal ve sosyal maliyetlere sebep olmaktadır. Bunlar da romatologların hastalık yönetiminde dikkate alması gereken konulardır.

- Öneriler, RA hastalarını hastalık süresine göre (erken vs yerleşik) değil, hedeflenen sonuç ve prognostik faktörlere göre düzenlenmiştir.

- Tedavi, her hastada hedef olan kalıcı remisyonu veya düşük hastalık aktivitesini amaçlamalıdır.

EULAR 2016 RA tedavi önerileri şöyledir:

1. RA tanısı konduğu anda, olabildiğince çabuk DMARD tedavisin başlanmalıdır.

2. Tedavi, her hastada kalıcı remisyon veya düşük hastalık aktivitesini hedef almalıdır.

3. Aktif hastalıkta hasta vizitleri sık sık (her 1-3 ayda) yapılmalıdır; eğer üç aya kadar iyileşme olmamışsa ve altı ayda hedefe ulaşılamadıysa, tedavi değiştirilmelidir. Metotreksat (MTX), ilk tedavi stratejisinin bir parçası olmalıdır. Klinik çalışmalarda MTX ile ACR70 yanıtı \%25 
oranında sağlanmaktadır. Yüksek dozlarda (25$30 \mathrm{mg} / \mathrm{hafta}$ ) ise \%40 düşük hastalık aktivitesi sağlamaktadır.

4. MTX'a kontrendikasyonu (veya erken intolerans) olan hastalarda, leflunomid ve sulfasalazin (ilk) tedavi stratejisi olarak değerlendirilmelidir.

5. RA tanısı konar konmaz DMARD tedavisine başlanmalıdır. Hedef, DMARD naiflerde remisyon, DMARD dirençli olanlarda ise düşük hastalık yanıtıdır. Hedef minimum altı ay kalıcı olmalıdır. Remisyon değerlendirmede ACR/EULAR Boolean, SDAI veya CDAI kullanılmalıdır. Hedefi belirlemede USG değil klinik ölçütler kullanılmalıdır. Tedavi ayarlanması için, MTX (ya da başka DMARD) tedavisinin optimizasyonu, eklem içi enjeksiyonlar ve ancak bu önlemler yetersiz/ ya da uygunsuz ise ilaç değişimi uygundur.

6. csDMARD tedavisi başlarken/değiştirirken değişik doz ve kullanım şekillerinde kısa süreli kortizon tedavi stratejisinin bir parçası olarak düşünülmeli ancak en kısa sürede kesilmelidir.

7. Kötü prognostik faktörlerin olmadığı durumlarda ilk csDMARD tedavisi ile tedavi hedefine ulaşılamazsa, diğer csDMARD'lar değerlendirilmelidir.

2013 önerisindeki metinde: kortikosteroidler, düşük dozda ( $<7,5 \mathrm{mg} / \mathrm{gün}$ ) ve altı aya kadar ve ilk tedavi stratejisinin bir parçası olarak değerlendirilmişti. Çeşitli çalışmalarda $250 \mathrm{mg}$ pulse, $120 \mathrm{mg}$ depo-kortizon, $30 \mathrm{mg} /$ gün kortizon gibi değişik steroid doz önerileri mevcuttur. Bu nedenle yeni önerilerde doz ve yöntem hekime bırakılmış. Eski önerideki ilk tedavi ibaresi yerine her yeni csDMARD başlangıcı denilmiş. Biyolojik ve hedefe yönelik sentetik DMARD'lar hızlı etkili olduğundan ek kortizon önerilmemiş. Tercihen üç en geç altı ayda kesilmesi vurgulanmış. Yeni önerilerde kombinasyon tedavisi hekime bırakılıyor. Başlanan ilaca erken intolerans tedavi başarısızlığı kabul edilmiyor, aynı faz kabul ediliyor. İlk klasik DMARD başarısızlığında ikinci bir csDMARD (+kortizon) tek başına verilebiliyor. 2013 önerileri: hedefe yönelik sentetik DMARD (ts DMARD) başlanması biyolojik DMARD (bDMARD) başarısızlığı sonrası idi. Hedefe yönelik sentetik DMARD'larla yeni veriler var ama bDMARD'ların uzun süreli veritabanları olamsı, bu ilaçları öne çıkarıyor. 2013 önerilerinde RTX için "özel durumlarda kullanılır" denilirken yeni önerilerde bu madde yer almamaktadır. Biyolojik ya da tsDMARD başlamada öne çıkan bir ilaç belirtilmemektedir).

8. Kötü prognostik faktörlerin olduğu durumlarda ilk csDMARD tedavisi ile tedavi hedefine ulaşılamazsa, bir bDMARD eklenmeli veya bir tsDMARD düşünülmelidir; güncel pratikte bir bDMARD ile başlanmaktadır.

9. bDMARD ve tsDMARD, bir csDMARD ile kombine edilmelidir; komedikasyon olarak csDMARD kullanamayan hastalarda, IL-6 yolağı inhibitörleri ve tsDMARD'lar, diğer bDMARD'lara kıyasla bazı avantajlar sağlayabilir.

10. bDMARD ve tsDMARD'a yanıt alınamazsa, başka bir bDMARD veya tsDMARD değerlendirilebilir; eğer bir TNF inhibitörüne yanıt alınamazsa, hastalar başka bir TNF inhibitörü veya başka bir etki mekanizması ajanını kullanabilirler.

11. Glukokortikoid kesilmesinden sonra hasta kalıcı remisyondaysa bDMARD'ların da doz arası, özellikle bu tedavi bir csDMARD ile kombine ise, açılabilir.

12. Bir hasta kalıcı remisyonda ise csDMARD ın doz arası açılması değerlendirilebilir. (JAK inhibitörleri diğer bDMARD'lar (halen güncel pratik olarak vurgulanmaktadır) ile birlikte birinci basamak post-csDMARD olarak konumlandırılmıştır. EMA veya FDA onaylı, tedavi yolağındaki biyosimilar veya orjinaller arasında pozisyonlandırma açısından bir tercih belirtilmemiştir. bDMARD monoterapisindense, bDMARD'ların csDMARD'lar (MTX) ile kullanımı önerilmektedir.

Tüm bDMARD'lar MTX ile kombine edildiğinde monoterapiye kıyasla superior etki göstermişlerdir. bDMARD'lar ve tsDMARD'lar, bir csDMARD ile kombine edilmelidir. Doz azaltımı veya ara açımı, tüm bDMARD'lar ile güvenli ve düşük alevlenme riski ile yapılabilir. İlacı kesmek, yüksek alevlenme riski ile ilişkilidir. Çoğu hasta iyi durumuna aynı bDMARD'lara başlanması ile ulaşabilirler. Jak inhibitörlerine yanıtsızlık sonrasında bDMARD'ların etkililik ve güvenliliği bilinmemektedir. Aynı şekilde önceki Jak inhibitörüne yetersiz yanıttan sonra bir Jak inhibitörünün etkililik ve güvenliliği de bilinmemektedir.

EULAR 2016 önerilerindeki başlıca değişiklikler şöyledir: MTX dozunun hızlıca yükseltilmesi, gereğinde 25-30 mg/haftaya çıkarılması daha kuvvetli vurgulanmaktadır. Klasik DMARD kombinasyonu yerine klasik DMARD ve kortizon 
kombinasyonu öne çıkmaktadır. Düşük doz kortizon yerine, değişik kullanım yolları göz önüne alınarak "kısa süre" kortizon vurgulanmaktadır. Kortizon, klasik DMARD'ların her değişiminde kullanılabiliyor. Klasik DMARD kombinasyonu tercihi romatologa bırakılıyor. EULAR/ACR Boolean remisyon yanıtı, SDAI, CDAI veDAS28'e göre daha çok tercih edilmiştir. Bütün biyolojikler ve hedefe yönelik sentetik DMARD'lar (daha az tercihen) sıra gözetmeksizin kullanılabiliyor. Kötü prognostik faktörlerin varlığında csDMARD yanıtsızlığı sonrası bDMARD'ların ve daha az tercihen tsDMARD'ların kullanımı önerilmektedir (9).

2015 ACR tedavi kılavuzu hazırlamıştır (10).

Bu kılavuzdaki bazı tanımlar şöyledir:

Yerleşik RA: RA hastalık semptom süresi $>6$ ay veya 1987 ACR RA klasifikasyon kriterlerini karşılıyor olmak

DMARD / Biyolojik başarısızlığı: Etkililikte azalma, arzu edilen etkiyi görememe ya da yan etki nedeniyle tedavinin başarısızlığı

Sekonder biyolojik başarısızlığı: Önceden etkili olan biyolojik ajanın zamanla etkililiğin azalması

RA tedavisinde optimal doz:

1) Hasta önceliklerine göre hasta-klinisyen ortak karar doğrultusunda belirlenmiş olan tedavi hedefine ulaşma için dozlama

2) Tedavi arttırma ya da değiştirmeden önce verilen en az 3 aylık tedavi

Tedavideki ana prensipler şöyledir:

1. İstisna olanlara değil, yaygın klinik senaryolara yoğunlaşılmalıdır.

2. Bu önerilerde maliyet göz önünde bulundurulmuştur ancak maliyet etkililik analizi yapılmamıştır.

3. RA hastalarında karşılaştırma için ACR tarafından önerilen bir ölçüm yöntemi kullanılmalıdır.

4. RA hastalarında fonksiyonel durum standardize ve onaylı bir yöntem kullanılarak en az yılda bir, eğer aktifse daha sık, değerlendirilmelidir (örn: HAQ, HAQ II, Multidimensional HAQ, PROMIS).

5. Eğer hastada düşük hastalık aktivitesi varsa ya da remisyondaysa, tedavi değişikliği sadece hasta ile tedavi eden hekimin ortak görüşüne bağlıdır. Keyfi olarak, sigorta şirketleri ya da ödeme koşulları yüzünden tedavi değişikliği önerilmemektedir.

6. Tedavi önerilerinde bir ilacın diğerine tercih edilmiş olması, tercih edilen ilacın önerilen ilk seçenek olduğu anlamına gelir. Ancak bir ilacın diğer ilaca tercih edilmiş olması, diğer ilacın bu durumda kontrendike olduğu anlamına gelmez, halen belli durumlarda kullanılma potansiyeli mevcuttur.

ACR 2016 Romatoid artrit tedavi önerileri şöyledir:

1. Hastalık aktivite seviyesi dikkate alınmaksızın hedefsiz bir yaklaşım yerine treat-to-target stratejisini kullanılmalıdır.

2. Eğer hastalık aktivitesi düşük ise ve hasta hiç DMARD kullanmamışsa, ikili tedavi yerine DMARD monoterapisi (tercihen MTX), üçlü tedavi yerine DMARD monoterapisi (tercihen MTX) önerilir.

3. Eğer hastalık aktivitesi orta veya şiddetli ise ve hasta hiç DMARD kullanmamışsa, İkili tedavi yerine DMARD monoterapisi, üçlü tedavi yerine DMARD monoterapisi önerilir.

4. Eğer hastalık aktivitesi DMARD monoterapisine rağmen (glukokortikoidle veya değil) orta veya şiddetli kalırsa; DMARD monoterapisine devam etmektense, DMARD kombinasyonu veya TNF inhibitörü veya nonTNF biyolojik (tüm seçimler tercihen MTX'la veya MTX'sız) kullanılmalıdır.

5. Eğer hastalık aktivitesi DMARD'sız TNF inhibitörü terapisine rağmen orta veya şiddetli kalırsa, tek başına TNF inhibitörüne devam etmektense TNF inhibitörüne bir veya iki DMARD eklenmelidir.

6. Eğer hastalık aktivitesi tek başına TNF inhibitörüne rağmen orta veya şiddetli kalırsa:

Başka bir TNF inhibitörü (+/- MTX) yerine bir nonTNF biyolojik (+/- MTX) kullanılmalı;

Tofasitinib (+/- MTX) yerine ise bir non-TNF biyolojik (+/- MTX) kullanılmalıdır.

7. Eğer hastalık aktivitesi tek başına non-TNF biyolojik kullanmına (+/- MTX) rağmen orta veya şiddetli kalırsa, tofasitinib (+/- MTX) yerine başka bir non-TNF biyolojik (+/- MTX) kullanılmalıdır

8. Eğer hastalık aktivitesi çoklu (2+) ardarda TNF inhibitör terapisine rağmen orta veya yüksek kalırsa, ilk olarak başka bir TNF inhibitörü veya tofasitinib (+/- MTX) yerine bir non-TNF biyolojik (+/-MTX) kullanılmalıdır.

9.Eğer hastalık aktivitesi çoklu TNF inhibitör terapisine rağmen orta veya şiddetli kalırsa ve non-TNF biyolojik bir seçenek değilse, başka 
bir TNF inhibitörü (+/- MTX) yerine tofasitinib (+/- MTX) kullanılmalıdır.

10. Eğer hastalık aktivitesi en az bir TNF inhibitörü ve en az bir non-TNF biyolojik kullanımına rağmen orta veya şiddetli kalırsa: Tofasitinib yerine ilk olarak başka bir non-TNF biyolojik (+/- MTX) kullanılmalı, eğer hastalık aktivitesi orta veya şiddetli kalırsa, başka bir TNF inhibitörü yerine tofasitinib (+/- MTX) kullanılmalıdır.

11. Eğer hastalık aktivitesi DMARD, TNF inhibitörü veya non-TNF biyolojik kullanımına rağmen orta veya şiddetli kalırsa, kısa dönem düşük doz GC eklenmelidir.

12. Eğer hastalar DMARD, TNF inhibitörü veya non-TNF biyolojik kullanırken hastalık alevlenirse, kısa dönem mümkün olduğunda düşük doz ve kısa süre boyunca glukokortikoid eklenmelidir.

13. Eğer hasta remisyonda ise, DMARD tedavisi, TNF inhibitörü, non-TNF biyolojik veya tofasitinib tedavisi azaltılmalıdır.

14. Eğer hastalık aktivitesi düşük ise, tedaviyi kesmektense, DMARD tedavisi, TNF inhibitörü, non-TNF biyolojik veya tofasitinib tedavilerine devam edilmelidir.

15. Eğer hasta remisyonda ise, tüm RA tedavileri kesilmemelidir (10).

APLAR (Asia Pacific League of Associations for Rheumatology) 2015 romatoid artrit önerileri, tedavi ve hasta takibini kapsamaktadır (11). APLAR 2015 önerilerinde negatif prognostik faktörler: ACPA veya RF pozitifliği, ESH veya CRP yüksekliği ve radyolojik erozyon kanıtı olarak belirlenmiştir. Tedavi öncesi önerilen araştırma ve görüntülemeler: Tam kan sayımı, komorbiditeler, hamilelik ve laktasyon, BFT, KCFT, ekstraartiküler belirtiler, aşı durumu, göğüs radyografisi, infeksiyonlar I (TB, viral hepatit serolojisi) kapsamaktadır. Oral kortikosteroid monoterapisi önerilmez. Hastada negatif prognostik faktör yoksa DMARD monoterapisine başlanması, (MTX +/kortikosteroid), (MTX kontrendike ise;
Leflunomid, sulfasalazin, hidroksiklorokin siklosporin, kas içi altın, takrolimus, vb) önerilir.

NSAID ilaçlar, semptomatik tedavide kullanılabilir. Hedef remisyon veya düşük hastalık aktivitesidir (LDA). Negatif prognostik faktör varsa, DMARD (+/-kortikosteroid) kombine tedavisi başlanması, altı ayda yetersiz yanıt varsa MTX+ biyolojik tedavisi önerilir. Altı aylık takipte yetersiz yanı varsa biyolojiğin değiştirilmesi önerilir. 6-12 ay devam eden remisyon/LDA sağlanması durumunda, hasta ve doktor ortak kararı, önce steroid sonra biyolojiğin kesilmesi, DMARD'ların da olabilecek en düşük dozda ayarlanması önerilir. Tofasitinib ise, biyolojik DMARD'ların başarısız olması durumunda önerilmiştir (11).

RA'te erken tanı ( $<3$ ay), erken ve etkin tedavi, hastalığın seyrini değiştirebilmektedir (12). RA'te klinik remisyon artık başarılabilir bir hedeftir. Erken agresif tedavi, remisyon oranlarını etkilemektedir (13). Ancak gerçek yaşam verilerinde her zaman hedefe ulaşabilmek mümkün olmamaktadır. Norveç kayıt sisteminde takip edilen 2778 RA hastasının 2019 yılı verisinde, 2 yıllık takip sonunda, DAS28 (ESR) ile 6. ayda yetersiz yanıt oranı \%33,9 iken, 12. ayda yetersiz yanıt oranı $\% 47,2$ olarak belirlenmiştir (14). İsviçre kayıt sistemi 2015 yılı yayınında ise, 3111 hastanın, bir yıllık bDMARD tedavisi verileri DAS28 değerlendirildiğinde bDMARD+ cs DMARD kombinasyonunun, bDMARD monoterapisinden daha efektif olduğu bildirilmiştir (15). Tedaviye biyolojik ilaçların erken dönemde eklenmesinin tedavi başarısını artırdığı bildirilmiştir (16).

\section{Sonuç}

Sonuç olarak uzun ve kalıcı remisyon hedefi halen güç gibi görünmekle birlikte, hazırlanan kılavuzlar ışığında, belirlenen tedavi hedeflerine ulaşana dek hastaların sıkı takibi ve uygun tedavi modifikasyonları ile hedef daha ulaşılabilir görünmektedir. Gelecekte yapılacak daha kapsamlı çalışmalar ile bireyselleştirilmiş tedavilerin geliştirilmesi mümkün olabilecektir.

\section{Kaynaklar}

1. Smolen JS, Aletaha D, McInnes IB. Rheumatoid arthritis. Lancet 2016;388:2023-38.

2. Bergstra SA, Allaart CF. What is the optimal target for treat-to-target strategies in rheumatoid arthritis? Curr Opin Rheumatol 2018;30: 282-7. 
3. Leeb BF, Brezinschek HP, Rintelen B. RADAI-5 and electronic monitoring tools. Clin Exp Rheumatol 2016; 34: 5-10.

4. Gomez-Centeno A, Rubio-Romero E, Ovalles JG, et al. Clinical and therapeutic management of rheumatoid arthritis with biological disease-modifying antirheumatic drugs: RADAR study. Rheumatol Int 2019 Aug 8 doi: 10.1007/s00296-019-04378-6.

5. Pincus T, Yazici Y, Bergman MJ. RAPID3, an index to assess and monitor patients with rheumatoid arthritis, without formal joint counts: similar results to DAS28 and CDAI in clinical trials and clinical care. Rheum Dis Clin North Am 2009; 35: 773-8.

6. Johnson TM, Register KA, Schmidt CM, O'Dell JR, Mikuls TR, Michaud K, England BR. Correlation of the Multi-Biomarker Disease Activity Score With RheumatoidArthritis Disease Activity Measures: A Systematic Review and Meta-Analysis. Arthritis Care Res (Hoboken) 2019; 71: 1459-72.

7. van Tuyl LH, Felson DT, Wells G, Smolen J, Zhang B, Boers M; American College of Rheumatology; European League against Rheumatism Committee to Define Remission for Clinical Trials. Evidence for predictive validity of remission on long-term outcome in rheumatoid arthritis: a systematic review. Arthritis Care Res (Hoboken) 2010; 62: 108-17.

8. Bykerk VP, Massarotti EM. The new ACR/EULAR remission criteria: rationale for developing new criteria for remission. Rheumatology (Oxford) 2012; 51: 16-20.

9. Misra DP, Agarwal V, Sharma A, Wakhlu A, Negi VS. 2016 update of the EULAR recommendations for the management of rheumatoid arthritis: a utopia beyond patients in low/middle income countries? Ann Rheum Dis 2017;76(11):e47. doi: 10.1136/annrheumdis-2017-211446.

10. Singh JA, Saag KG, Bridges SL Jr, et al; American College of Rheumatology. 2015 American College of Rheumatology Guideline for the Treatment of Rheumatoid Arthritis. Arthritis Care Res (Hoboken) 2016; 68: 1-25.

11. Lau CS, Chia F, Harrison A, Hsieh TY, Jain R, Jung SM; Asia Pacific League of Associations for Rheumatology. APLAR rheumatoid arthritis treatment recommendations. Int J Rheum Dis 2015; 18: 685-713.

12. Breedveld FC, Kalden JR. Appropriate and effective management of rheumatoid arthritis. Ann Rheum Dis 2004; 63: 627-33.

13. Tanaka Y. Current concepts in the management of rheumatoid arthritis. Korean J Intern Med 2016; 31: 210-8.

14. Olsen IC, Lie E, Vasilescu R, Wallenstein G, Strengholt S, Kvien TK. Assessments of the unmet need in the management of patients with rheumatoid arthritis: analyses from the NOR-DMARD registry. Rheumatology (Oxford) 2019; 58: 481-91.

15. Gabay C, Riek M, Scherer A, Finckh A; SCQM collaborating physicians. Effectiveness of biologic DMARDs in monotherapy versus in combination with synthetic DMARDs in rheumatoid arthritis: data from the Swiss Clinical Quality Management Registry. Rheumatology (Oxford) 201; 54): 1664-72.

16. Mease PJ. Adalimumab in the treatment of arthritis. Ther Clin Risk Manag 2007; 3: 133-48. 